\section{JTI}

JOURNAL OF

TRAUMA AND INJURY

\title{
Case Series: Successful Resuscitation of Severe Facial Injuries Caused by a Chainsaw
}

\author{
Han Joo Choi, M.D., Ph.D. \\ Department of Emergency Medicine, Dankook University Hospital, Cheonan, Korea
}

Received: August 16, 2019

Revised: September 16, 2019

Accepted: September 24, 2019

\section{Correspondence to}

Han Joo Choi, M.D., Ph.D.

Department of Emergency Medicine, Dankook University Hospital,

201 Manghyang-ro, Dongnam-gu,

Cheonan 31116, Korea

Tel: +82-41-550-6840

Fax: +82-41-556-0524

E-mail: iqtus@hanmail.net

The treatment outcome remains poor of severe facial injuries because of the high risk of compromised airway or massive bleeding. We experienced two successful treatment cases of severe facial injury by the chainsaw. A 52 -year-male had his face injured by the chainsaw during his work. He was transferred to the Level I trauma center using the Doctor-Helicopter. During his flight, bleeding control was tried and the information was given to the trauma surgeons before his arrival. His consciousness was alert and the vital signs were stable. The crushing wound, mandible open fracture, deep laceration of tongue, lip, neck and arterial bleeding were noted around his mandible. Nasotracheal intubation was performed under the bronchoscope-guided. Emergency operation (open reduction \& internal fixation, primary repair with neurorrhaphy) was performed. At 30 hospital days, he was discharged with facial palsy on left mandibular area. A 30-yearmale had his face injured by the chainsaw. He was transferred to our Level I trauma center from the local hospital. The deep-mutiple lacerations on right upper eyelid and forehead with the bony exposure were noted. The vital signs were stable and emergency operation was performed. He was discharged at 20 hospital days. Bone loss or tissue loss were not devastating than we expected even though the injury was occurred by the chainsaw. Aggressive treatment including airway manipulation or bleeding control and maximal opportunity of therapy are absolutely needed.

Keywords: Facial injuries; Crush injuries; Emergency treatment

\section{INTRODUCTION}

Chainsaw, a mechanical saw widely used by individuals at homes and construction industry fields, can cause various devastating injuries to multiple body parts. Despite few reported studies, little is known about the incidence and characteristics of chain-

This is an Open Access article distributed under the terms of the Creative Commons Attribution Non-Commercial License (http://creativecommons.org/licenses/by-nc/4.0/) which permits unrestricted noncommercial use, distribution, and reproduction in any medium, provided the original work is properly cited. 
saw-related injuries [1-5]. Emergency physicians (EPs) often encounter patients with chainsaw-related injuries in emergency department (ED) in South Korea. In this study, we report two cases of severe facial injuries caused by a chainsaw that were successfully treated with initial systematic emergency care and definitive surgery.

\section{CASE REPORT}

\section{Case 1}

A 52-year-old male patient severely injured his face with a chainsaw during his logging work. He had cut branches without facial shield. The blade of chainsaw hit his face through unintentional body motion due to slip. He was transferred to the Level I trauma center by a doctor-helicopter. He was conscious, and the airway was secured despite massive facial injury. During scene inspection, EP noted crushing wound with open mandibular fracture; deep lacerations of the tongue, lip, and neck; and arterial bleeding around his mandible. The patient's blood pressure and heart rate were $135 / 80 \mathrm{mmHg}$ and 100 beats/min, respectively. He leaned against the seat and raised his head to maintain the airway patency during helicopter transportation. The wounds were compressed with hemostatic gauzes. Trauma team activation was performed before helicopter arrival through social network system hotline. Bronchoscope-guided nasotracheal intubation was performed after ED arrival. Facial crushing wounds, open mandibular fracture, and partial tongue laceration were noted, and neurovascular injury was highly suspected based on the physical examinations performed after intubation (Fig. 1). Moreover, mild metabolic acidosis was noted ( $\mathrm{pH} 7.3, \mathrm{PaO}_{2} 90 \mathrm{mmHg}, \mathrm{PaCO}_{2} 30 \mathrm{mmHg}$, bicarbonate $15 \mathrm{mEq} / \mathrm{L}$, base excess $-4.1 \mathrm{mEq} / \mathrm{L}$ ), and hemoglobin level was $9 \mathrm{~g} / \mathrm{dL}$. For the first time, a successful primary repair was not expected due to massive bone and tissue loss. Emergency operation (open reduction and internal fixation and primary repair with neurorrhaphy) was performed by the trauma team, and the patient was discharged with facial palsy on the left mandibular area at 30 days postoperatively (Fig. 2).

\section{Case 2}

A 30-year-old male patient injured his face with a chainsaw. He was transferred to our Level I trauma center from a local hospital. Multiple deep lacerations on the right upper eyelid and forehead with bony exposure were noted. He was conscious, and the vital signs were stable. Emergency operation was performed by the trauma team, and he was discharged at 20 days postoperatively (Fig. 3).

\section{DISCUSSION}

In case of chainsaw-related injuries, experienced EPs are aware of the potential risk of treatment in patient. However, little is known about the incidence and characteristics of these injuries. Studies reported on chainsaw-related injuries are mostly case reports. The annual number of patients with chainsaw-related injuries was reported to be 23,000 in the United States [6]. Most of the patients were
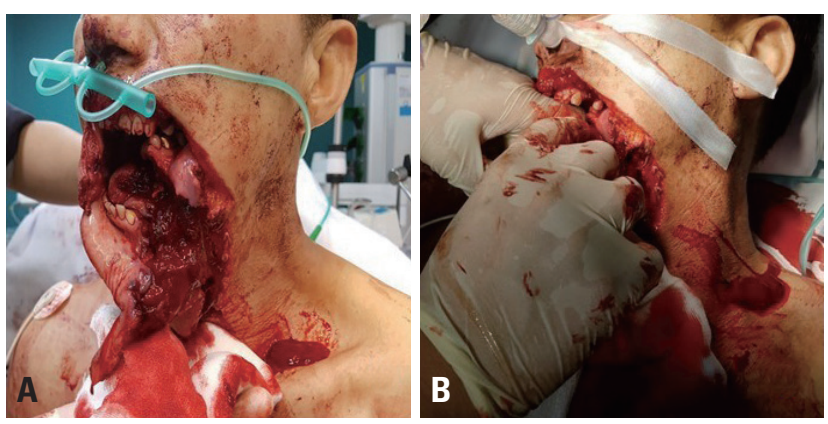

Fig. 1. Facial crushing injuries caused by a chainsaw (A) before and (B) after nasotracheal intubation, which was performed at the resuscitation room at the trauma center.
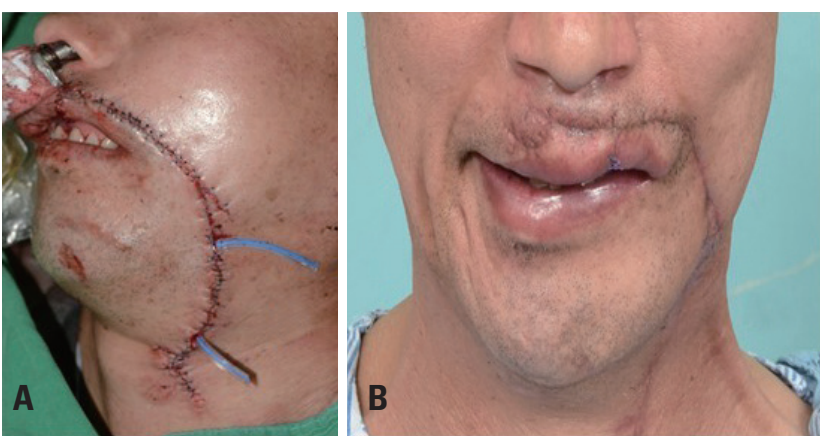

Fig. 2. (A) Primary repair with emergency open reduction without graft surgery of bone and skin. (B) Neuronal palsy was remained after surgery. 


\section{JTI}

male (95\%), and the injuries most frequently occurred in the age group of 30-59 (57\%). Although, there is no defined index to estimate the incidence of chainsaw-related injuries in South Korea, the frequency can be estimated according to the Korean government reports on the accidents in industrial fields. According to the report of the Occupational Safety and Health Research Institute in Korea, the number of patients who experienced amputation, cut, or stab injuries was 3,680 (8\%) during 2013-2017 [7]. Additionally, the Ministry of Employment and Labor in Korea reported that there were 8,752 patients with amputation, cut, and stab injuries in 2017, and this constituted $10 \%$ of the total industrial accidents [8].

In the United States, $58 \%$ of the injuries occur at home [6], whereas in Europe, most of the accidents occur at industrial fields [9]. This difference is based on different cultural techniques in using these tools. This factor should be considered while collecting data in South Korea. In the United States, the most frequent type of chainsaw-related injury is laceration (81\%), which most frequently injures hands (28.8\%), knees (17.6\%), and calves (12.5\%) [6]. The injury pattern in the United States is different from that in the Europe. Injuries caused by fallen objects while operating a chainsaw are more frequently observed $(47.7 \%)$ than direct injuries caused by a chainsaw itself (39.3\%). In the case of injuries cause by fallen objects,

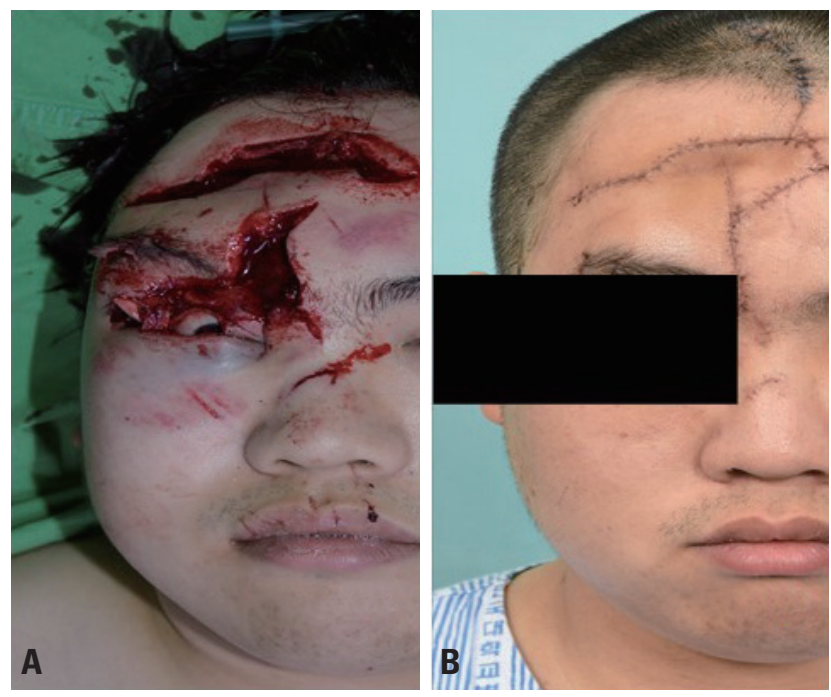

Fig. 3. (A) Multiple deep lacerations on the right upper eyelid and forehead with bony exposure were noted on emergency department arrival. (B) Primary closure was performed without complications. heads (34.8\%), torsos (25.0\%), and legs (16.8\%) are commonly injured [9].

The basic treatment concept for chainsaw-related injuries is not different from that for other types of injuries. Patients with superficial wounds can be discharged from ED after primary repair and can visit the outpatient clinic for follow-up purposes. Only 3.6\% of the total patients with chainsaw-related injuries are hospitalized for care [6]. Initial emergency care including airway patency is paramount in the cases of facial injury due to the possibility of the compromised airway or vascular injury. In the case 1, the patient was transported by a doctor-helicopter. In South Korea, board-certificated EPs are usually present on such helicopters. Therefore, initial advanced airway maneuver such as nasotracheal intubation is performed on patient by the EP on board. In this case, the patient was conscious and the airway patency was maintained despite the crushing wound, and thus nasotracheal intubation was not performed at the scene or in the helicopter. However, we focused on the bleeding control. Moreover, aspiration of blood from the oral cavity is possible in supine position; he thus leaned against the seat in head-up position to prevent the aspiration. Thereafter, active bleeding was not observed during the transportation to hospital. After ED arrival, bronchoscope-guided nasotracheal intubation was performed to minimize the additional injury to the perioral area. Emergency internal fixation surgery without skin graft was successfully performed by the trauma team.

To prevent any chainsaw-related injuries, it is necessary to wear protective equipment and to be familiar with properly handling the tool. In most countries, statutory guidance on using a chainsaw is inadequate; however, accidents are believed to occur despite cautious use.

Trauma team members do not frequently encounter patients with chainsaw-related injuries. According to the Advanced Trauma Life Support guidelines, the basic concept of airway-breathing-circulation is paramount in emergency care. Maintaining airway patency is the priority after facial injuries. In this study, although injuries were caused by a chainsaw, bone or tissue loss was not as devastated as expected and the primary repair was thus possible. Once the airway patency and stabilization of the vital signs have been achieved, it is possible for patients to 
resume their daily life. Hence, we suggest that aggressive treatment, including airway manipulation or bleeding control and maximal therapeutic opportunity, is required in cases of severe facial injuries related to chainsaw.

\section{ACKNOWLEDGEMENTS}

Thank you for all ED and trauma team members of Dankook university hospital attributing appropriate care for these cases.

The present research was conducted by the research fund of Dankook University in 2017.

\section{REFERENCES}

1. Brown AF. Chainsaw penetrating neck injury. Emerg Med J 1995;12:134-37.

2. Koehler SA, Luckasevic TM, Rozin L, Shakir A, Ladham S, Omalu B, et al. Death by chainsaw: fatal kickback injuries to the neck. J Forensic Sci 2004;49:345-50.

3. Marshall SW, Kawachi I, Cryer PC, Wright D, Slappendel C, Laird I. The epidemiology of forestry work-related injuries in New Zealand, 1975-88: fatalities and hospitalizations. N Z Med
J 1994;107:434-37.

4. Moreschi C, Da Broi U, Cividino S, Gubiani R, Pergher G. Neck injury patterns resulting from the use of petrol and electric chainsaws in suicides. Reports on two cases. J Forensic Leg Med 2014;25:14-20.

5. Lindroos O, Burström I. Accident rates and types among self-employed private forest owners. Accid Anl Prev 2010;42: 1729-35.

6. Hammig B, Jones C. Epidemiology of chain saw related injuries, United States: 2009 through 2013. Advances in Emergency Medicine 2015;2015:459697.

7. Occupational Safety \& Health Research Institute (OSHRI). News release for the annual numbers of injured workers from 2013 to 2017 [Internet]. Ulsan: OSHRI 2018 [cited 2018 Nov 19]. Available from: http://www.kosha.or.kr/kosha/data/industrialDisasterStatistics.do? mode $=$ view\&articleNo=398890\&article.offset $=0$ \&articleLimit $=10$.

8. Ministry of Employment and Labor. Statistics of the Korean industrial disasters on 2017 [Internet]. Sejong: Ministry of Employment and Labor 2018 [cited 2018 Apr 27]. Available from: https://www.moel.go.kr/policy/policydata/view.do?bbs_ seq $=20180400725$.

9. Cividino SRS, Gubiani R, Pergher G, Dell'Antonia D, Maroncelli E. Accident investigation related to the use of chainsaw. J Agric Eng 2013;44(s2):686-9. 